\title{
Herbário virtual e universidade: biodiversidade vegetal para ensino, pesquisa e extensão
}

Virtual and university herbarium: plant biodiversity for teaching, research and extension

\author{
J. C. M. da Costa; F. C. A. Lucas*; M. A. F. Gois; V. M. Leão; G. de J. M. \\ Lobato
}

Centro de Ciências Sociais e Educação, Universidade do Estado do Pará, 66113-010, Belém/Pará, Brasil

*copaldoc@yahoo.com.br

(Recebido em 22 de março de 2016; aceito em 18 de abril de 2016)

\begin{abstract}
Coleções botânicas documentam a identidade e distribuição das espécies vegetais, sendo essenciais tanto em trabalhos básicos quanto aplicados. O herbário Prof ${ }^{\mathrm{a}}$. Dr $^{\mathrm{a}}$. Marlene Freitas da Silva (MFS), localizado na Universidade do Estado do Pará (UEPA) possui espaço consolidado desde 2011, contudo seu acervo é pouco explorado no ambiente acadêmico. Este estudo objetivou criar um Herbário Virtual para o MFS, na Universidade do Estado do Pará, visando o acesso on line de dados diversificados da biodiversidade vegetal amazônica, como forma de contribuir para maior integração e socialização de informações à sociedade. Foram realizadas entrevistas informais com aplicação de formulários semiestruturados à 48 pessoas que visitaram a exposição do herbário na Semana Acadêmica da universidade. A preparação da infraestrutura dos dados do acervo para disponibilização on line, incluiu melhorias da qualidade dos bancos de informações e imagens, criação da página virtual e instalação do Brahms on line. As verbalizações dos interlocutores exteriorizaram o desconhecimento da existência do espaço na UEPA, bem como suas reflexões acerca da importância do MFS na produção de conhecimentos, destacando sua função sociocultural. A criação do espaço virtual possibilitou maior conhecimento de toda a coleção, com 5.800 amostras, 2.700 espécies, pertencentes a 886 gêneros e 173 famílias botânicas. Ademais, há também a coleção de flores, frutos, sementes e plântulas, que estão associadas a 210 registros de exsicatas. A socialização on line da biodiversidade vegetal promoveu dentro da universidade maior valorização de bens que são patrimônios naturais da humanidade, além de contribuir com dados científicos para toda a sociedade.

Palavras-chave: Brahms on line, Coleções científicas, Espaço virtual
\end{abstract}

Botanical collections documentation identity and distribution of plant species and are essential both in basic jobs as applied. The herbarium Prof ${ }^{a}$. Dr. Marlene Freitas da Silva (MFS), located in Pará State University (UEPA) has consolidated space since 2011, but its collection is little explored in the academic environment. This study aimed to create a Virtual Herbarium for MFS, in Pará State University, seeking online access to diverse data from Amazon plant biodiversity as a way to contribute to greater integration and sharing of information to society. Informal interviews with application of semi-structured forms to 48 people who visited the herbarium display in Week Academic University were held. The preparation of the infrastructure of collection of the data to be available online, included improvements in the quality of banks of information and images, creating the virtual page and installation of Brahms online. The verbalization of the interlocutors externalized ignorance of the existence of space in UEPA as well as his thoughts about the importance of MFS in the production of knowledge, highlighting its sociocultural function. The creation of virtual space allowed greater knowledge of the entire collection, with 5.800 samples, 2.700 species belonging to 886 genera and 173 botanical families. In addition, there is also a collection of flowers, fruits, seeds and seedlings, which are associated with 210 herbarium records. Socialization online plant biodiversity promoted within the university greater appreciation of assets that are the heritage natural humanity and contribute with scientific data for the whole society.

Keywords: Brahms online, Scientific collections, Virtual space 


\section{INTRODUÇÃO}

O costume de usar plantas para diversos fins, como alimento, remédio, crença, abrigo, utensílios etc., é uma prática milenar, que no decorrer dessa longa história, sedimentou conhecimentos e cultura sobre os vegetais em diversas civilizações. Segundo Fry [1] a primeira coletora de plantas de que se tem registro foi a rainha Hatshepsut, uma faraó egípcia que reinou por cerca de 20 anos no século XV a.C. Estudos realizados numa gravura do seu templo revelaram madeiras perfumadas da Terra dos Deuses, um bocado de resina de mirra e árvores vivas de mirra. Ao todo, foram identificadas nesta ilustração 31 árvores aromáticas. Desde então, os colecionamentos passaram a ter significado como heranças culturais, testemunhos de histórias e acontecimentos [2]. No Brasil quinhentista, a colonização e expansão da sociedade brasileira com a pluralidade dos povos migrantes e locais, incrementou o acervo botânico do país [2]. Já na segunda metade do século XX, universidades e institutos de pesquisa voltaram-se ao estudo da flora brasileira e somaram maiores esforços na coleta e na descrição de espécies, buscando documentar em coleções científicas a riqueza florística do país [3].

Diante da diversidade vegetal atrelada a conhecimentos pretéritos e atuais, pesquisas na área da botânica Sistemática e Taxonômica possibilitam identificar e classificar as espécies com base em suas características morfológicas e filogenéticas, que contribuem com informações aplicáveis a áreas de florística, monitoramento, conservação, fitoquímica, dentre outras [4].

Estudos interdisciplinares [5,6] sobre a flora brasileira resultaram na descrição de muitas espécies para o Brasil, e algumas delas exclusivas no mundo. Publicações do Ministério do Meio Ambiente (MMA) indicaram que além das espécies endêmicas presente no país, há táxons que detém uma importância econômica mundial, como o abacaxi (Ananas comosus (L.) Merril), o amendoim (Arachis hypogaea L.), a castanha-do-Pará (Bertholletia excelsa Bonpl.), a mandioca (Manihot esculenta Crantz), o caju (Anacardium occidentale L.) e a carnaúba (Copernicia prunifera (Mill.) H.E.Moore).

A Amazônia é considerada a região que abriga a diversidade mais rica do planeta, com cerca de 40.000 espécies vasculares de plantas, sendo 30.000 endêmicas [7]. Por sua grande extensão territorial, crescente pressão antrópica e baixa densidade de coletas [4], existe constante preocupação com a perda de espécies, principalmente devido ao desenvolvimento mal planejado de ações políticas, econômicas e educacionais. Dados do Instituto do Homem e Meio Ambiente da Amazônia [8] apontaram que em janeiro de 2015 o desmatamento se concentrou no Mato Grosso (75\%) e Pará (20\%), com menor ocorrência em Rondônia (2\%), Amazonas (1\%), Tocantins (1\%) e Roraima (1\%).

Informações relativas ao desmatamento alertam para a necessidade urgente de salvaguardar dados das espécies e de seus ambientes. Nesse contexto, os herbários são coleções botânicas nas quais se encontram depositados e documentados a diversidade e riqueza da flora de uma determinada área [9]. Para Cavalheiro et al [4] estes ambientes preservam a identidade e distribuição das espécies vegetais, sendo de suma importância em trabalhos de base (taxonômica e florística) e estudos aplicados.

Para atender as crescentes demandas de catalogação dos herbários, bem como a disseminação do conhecimento e tomada de decisões sobre conservação e uso sustentável, Saraiva; Canhos [10] discutiram o papel das ferramentas computacionais que podem suprir lacunas de coletas de informações, armazenamento, acesso e divulgação. Exemplos da aplicação dessas inovações tecnológicas podem ser conferidos através do Centro de Referência em Informação Ambiental (CRIA) [11], que atualmente gerencia dados sobre plantas no Brasil, contabilizando 156 coleções, com 7.272.898 registros depositados, sendo 5.309.872 disponíveis em herbários virtuais.

Instituições de ensino e pesquisa abrigam diretórios informativos sobre os recursos vegetais com o intuito de auxiliar estudantes e professores em suas investigações. O Instituto Nacional de Ciência e Tecnologia (INCT) [12] revelou para o ano de 2015 a existência de 69 herbários localizados em universidade brasileiras, distribuídos nas seguintes regiões: Nordeste (24), Sul (16), Sudeste (14), Centro-Oeste (09) e a região Norte (06). No estado do Pará apenas dois herbários encontram-se credenciados ao INCT, Herbário Virtual da Flora e dos Fungos: o 
herbário (HBRA), do Instituto de Estudos Costeiros da Universidade Federal do Pará e o (MFS) Prof $^{a}$. Dr ${ }^{a}$. Marlene Freitas da Silva, da Universidade do Estado do Pará (UEPA).

Criado no ano de 2011, o herbário MFS nasceu no espaço acadêmico, e em 2015, ao alcançar o patamar de 5.000 amostras de plantas, se consolidou com o registro no diretório global Index Herbariorum, concedido pelo Jardim Botânico de Nova Iorque [13]. O acrônimo MFS foi dado em homenagem à Dra $^{a}$. Marlene Freitas da Silva (1937-2005), importante taxonomista da Amazônia especializada na família botânica Leguminosae (Fabaceae Lindl). Atualmente, além de estar credenciado na Rede Brasileira de Herbários (RBH), o MFS também faz parte do Sistema de Informação sobre a Biodiversidade Brasileira (SiBBr), da rede de informatização do Centro de Referência em Informação Ambiental (CRIA) e mais recentemente no Sistema Global de Informação sobre a Biodiversidade (GBIF)[14].

Em 2014, o MFS realizou uma grande exposição de suas coleções em alusão ao dia da botânica, levando ao espaço acadêmico da UEPA materiais e produtos coletados principalmente na região amazônica. A exposição obteve um quórum considerável, com cerca de 200 participantes, o que permitiu a integração do herbário com um público bastante diversificado, constituído por alunos e professores do Centro de Ciências Sociais e Educação (CCSE), funcionários de outros setores, bem como pessoas externas à universidade. Na ocasião, foram observados relatos quanto ao desconhecimento da importância de uma coleção de plantas, de seus bancos de informações e aplicabilidade em ensino, pesquisa e extensão.

Diante da problemática observada, este trabalho teve por objetivo criar um Herbário Virtual para o MFS na Universidade do Estado do Pará, visando o acesso on line de dados diversificadas da biodiversidade vegetal amazônica, como forma de contribuir para uma maior integração e socialização de informações à sociedade. Para tanto, foram formuladas as seguintes questões: Como é visualizado um herbário virtual? Um herbário virtual pode ser considerado um laboratório multiusuário?

\section{MATERIAL E MÉTODOS}

A criação do herbário virtual na universidade foi planejada a partir de dois momentos: 1 . Realização de entrevistas com aplicação de formulários que versavam a respeito das coleções botânicas, sendo direcionadas às pessoas que visitaram a exposição. Esta etapa foi indispensável na averiguação do que se espera encontrar em um herbário virtual; 2. Preparação da infraestrutura dos registros já existentes no MFS para que pudessem ser disponibilizados on line em formato utilizável para diferentes públicos.

\subsection{Entrevistas}

As entrevistas ocorreram no mês de junho de 2015, durante a realização da XX Semana Acadêmica promovida pelo CCSE, cujo tema era Educação e Diversidade. Durante este acontecimento, o herbário promoveu exposição e incluiu em sua programação momentos para entrevistar os visitantes, que espontaneamente se dirigiam a sessão do acervo do MFS.

Foram aplicados formulários semiestruturados [15], aos participantes da pesquisa. Essa técnica permite que o entrevistado discorra sobre o tema proposto, sem respostas condicionadas ou influenciadas pelo pesquisador [15]. Nos formulários constavam previamente definidas as seguintes questões: 1) O que é um herbário?; 2) Você já visitou um herbário?; 3) Você conhece o herbário MFS da UEPA?; 4) Como um herbário pode ajudar a universidade e a sociedade com conhecimentos diversos? Essas perguntas foram trabalhadas em um contexto informal, possibilitando a interação entre o entrevistador e o entrevistado, e buscando alcançar uma cobertura mais aprofundada a respeito do tema [16].

A seleção dos interlocutores da pesquisa obedeceu ao seguinte critério: apenas o visitante que mostrava interesse em conhecer a exposição era convidado a participar da entrevista, e isso acontecia antes do mesmo receber informações relacionadas ao herbário, como forma de garantir respostas menos influenciadas. Por último, após o envolvimento do entrevistado com os temas abordados no evento, finalizava-se com a quarta pergunta, com o propósito de analisar o 
entendimento e os significados das questões discutidas no evento. Na ocasião das entrevistas, foram consideradas percepções e demandas a partir dos olhares dos diferentes atores relacionados ao herbário: instituição, curadoria, alunos, apoio técnico, professores, pesquisadores e visitantes externos à universidade.

Os conteúdos apresentados no herbário virtual foram desenvolvidos com base nas respostas sugeridas com a pergunta "Como um herbário pode ajudar a universidade e a sociedade com conhecimentos diversos?" e a partir das próprias necessidades do herbário, de ampliar linhas de pesquisa e traduzir as expectativas de seus visitantes.

\subsection{Infraestrutura dos dados: melhoria da qualidade da informação disponibilizada no Herbário Virtual}

A coleção do herbário MFS é constituída prioritariamente por amostras provenientes de expedições realizadas na região amazônica. As áreas de registro incluem o estado do Pará, com 12 municípios, e os estados do Maranhão (6), Amazonas (4) e Amapá (2). Este acervo também se consolidou por meio de intercâmbios com herbários do estado do Pará (IAN - Instituto Agronômico do Norte; EMBRAPA Amazônia Oriental; MG - Museu Paraense Emílio Goeldi) e de outras regiões (FURB - Universidade Regional de Blumenau; FUEL - Universidade Estadual de Londrina).

Todos os registros estão catalogados no software Botanical Research and Herbarium Management System [17], bastante aplicado por suas múltiplas funcionalidades, que atendem as necessidades de implementação e manutenção de coleções digitalizadas. No BRAHMS cada amostra de planta é identificada com nome e número de coletor, descrição do vegetal em campo, nome popular, localidade (país, estado, cidade, coordenadas geográficas), nome da família e o nome científico.

Para que as informações do MFS fossem disponibilizadas com qualidade, e de forma livre e aberta a todos os interessados investiu-se em infraestrutura on line, que incluiu atualizações de dados, compartilhamento de serviços e ferramentas computacionais de apoio a análise da biodiversidade. Nas bibliotecas do BRAHMS foram investigados e filtrados erros de digitação, variações ortográficas, duplicidades de nomes, lacunas de georeferenciamento e padronizações de nomes de autores e coletores.

A atualização dos nomes científicos foi verificada junto às bases virtuais: Lista de Espécies da Flora do Brasil [18], Missouri Botanical Garden [19] e no The New York Botanical Garden [20]. Os nomes de coletores seguiram a padronização proposta pelo Herbarium Information Standards and Protocols for Interchangeof Data [21]. Nesta proposta é recomendado que o coletor seja citado da seguinte maneira: sobrenome com a primeira letra maiúscula, seguido por vírgula e espaço e iniciais do nome em letras maiúsculas, separadas por pontos (ex. Sobrenome, A.B.C.).

\subsubsection{Fotografias e Análise do Banco de Imagens}

Cada uma das 5.800 amostras de plantas do herbário deve possuir duas imagens correspondentes (da amostra inteira e da etiqueta de identificação). Portanto, a continuidade deste padrão foi verificada, bem como a qualidade da imagem quanto a nitidez e a presença de escala de medida de tamanho (Figura 1). 


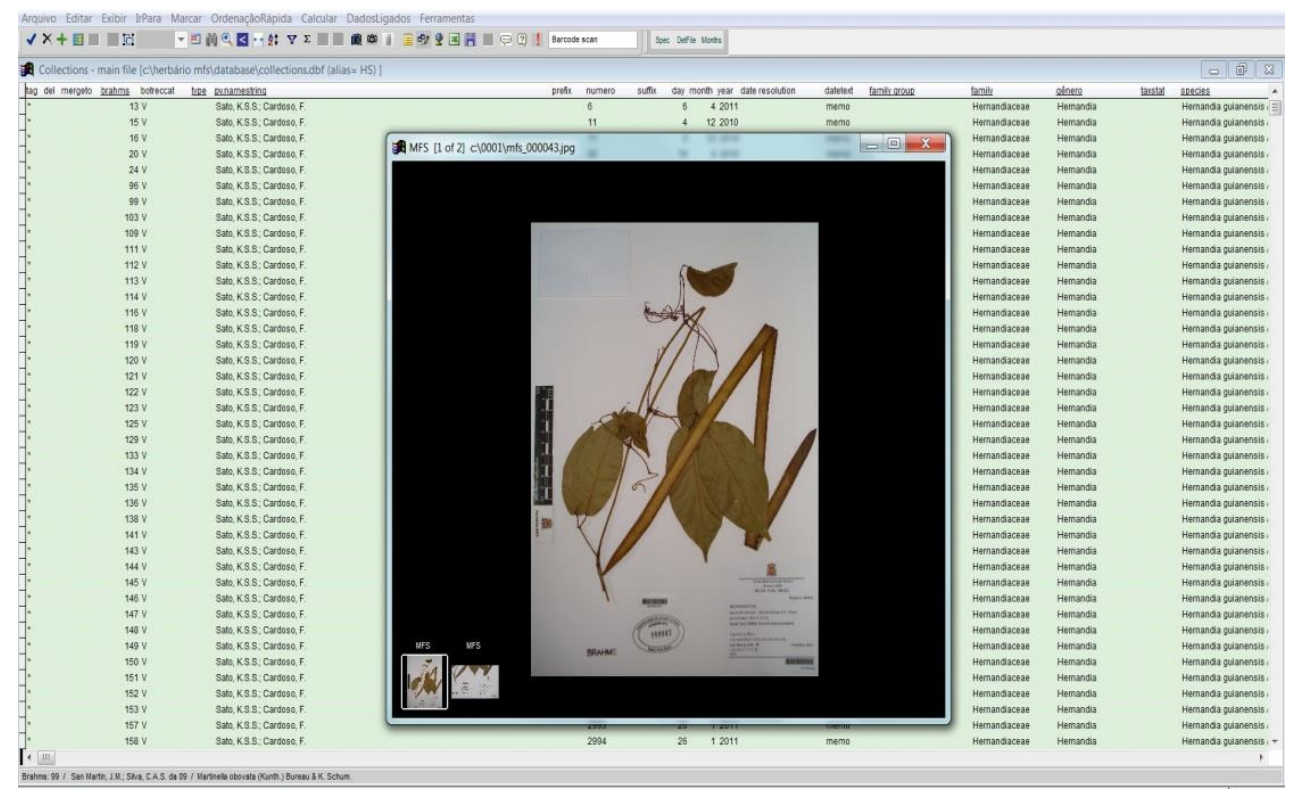

Figura 1: Banco de dados do herbário MFS com a imagem correspondente a amostra.

\subsubsection{Criação da página virtual do Herbário e instalação do BRAHMS on line}

Primeiramente, foi solicitada autorização junto ao Setor de Processamento de Dados da UEPA e a Assessoria de Comunicação (ASCOM), para a liberação do site do herbário na página principal da universidade, para facilitar o reconhecimento parte dos alunos e professores da instituição, bem como dar maior visibilidade. Dentro da página da UEPA, a ASCOM criou um ícone para direcionar o usuário até o herbário virtual.

A ferramenta empregada para a busca das espécies do MFS e todas as informações associadas, foi realizada com o auxílio de um instrumento que se encontra dentro do sistema BRAHMS denominado BRAHMS on line (BOL), desenvolvido por pesquisadores da Universidade de Oxford, que permite publicar em rede on line bases de dados de materiais botânicos [22]. A página criada pelo servidor BOL pode ser ampliada e preenchida com textos, imagens, hyperlinks, tabelas e downloads de arquivos. A instalação do BRAMHS on line foi conduzida seguindo o manual BRAHMS on line: Installation Guide [23].

Com objetivo de criar uma identidade para facilitar o reconhecimento do herbário MFS foi criada uma logomarca representada pela ilustração da árvore da castanha-do-pará, eleita a planta símbolo deste acervo.

\section{RESULTADOS E DISCUSSÃO}

\subsection{Percepções dos Entrevistados}

No decorrer da exposição participaram da pesquisa 48 interlocutores, sendo 10 homens e 38 mulheres, na faixa etária entre 11 a 64 anos. O público majoritário que compareceu à sessão do herbário esteve representado por estudantes, totalizando $85 \%$. Os demais, $15 \%$, foram visitantes externos ao meio acadêmico (autônomos, frentistas, profissionais de serviços gerais, xerocopista, dentre outros).

No momento dos diálogos foi expressado o que seria um herbário, com verbalizações que explicaram o termo de várias maneiras, segundo suas concepções visuais (observação durante a exposição), conhecimento prévio da área ou julgamento pela etimologia da palavra (mencionados por alunos de letras, principalmente). As definições mais citadas estão representadas na Tabela 1. 
Tabela 1: Definições de um herbário segundo os entrevistados da pesquisa.

\begin{tabular}{lcc}
\hline Definições & Frequência & Percentual (\%) \\
\hline Exposição de plantas & 2 & 4 \\
Lugar de cultivo de plantas & 3 & 7 \\
Local que cataloga plantas & 5 & 10 \\
Local onde há várias espécies de plantas & 5 & 10 \\
Lugar em que se estuda/pesquisa plantas & 5 & 10 \\
Está relacionado à botânica & 6 & 13 \\
Coleções de plantas & 6 & 13 \\
Não respondeu & 16 & 33 \\
\hline Total & 48 & 100 \\
\hline
\end{tabular}

Instigados sobre o que seria um herbário, $60 \%$ das respostas positivas conceituaram-no relacionando a colecionamentos, estudos e exposições, o que está de acordo com o entendimento deste local, onde materiais vegetais são desidratados e catalogados para fins de conservação, ensino e pesquisa para gerações futuras [24]; contudo, 33\% não responderam e 7\% o denominaram como lugar de cultivo de plantas (Tabela 1). O não entendimento do significado de uma coleção faz refletir sobre a falta de divulgação e investimento deste espaço nas instituições que os abrigam. Para Záchia [25] a universidade deveria cumprir um papel chave nesse sentido, priorizando objetivos maiores como os herbários e jardins botânicos que possibilitam o acesso à biodiversidade, em detrimento de prazer individual e sucesso acadêmico.

A respeito da visita a uma coleção, $92 \%$ dos interlocutores afirmaram nunca terem ido a um herbário, e apenas $8 \%$ responderam positivamente, citando o MFS da UEPA, o MG, Museu Paraense Emilio Goeldi, Belém, Pará e o Herbário JBB Jardín Botánico José Celestino Mutis, Bogotá, Colômbia. A questão da ausência do conhecimento in loco perpassa por vários motivos. No caso do MFS, $88 \%$ declararam não saber que a universidade possuía um herbário, conhecendo-o com a semana acadêmica; e $12 \%$ aprenderam sobre coleções científicas durante a semana do calouro, e na exposição pelo Dia Nacional da Botânica, ocorrida em 2014. Contestando o que foi evidenciado neste estudo, Santos [26] destacou a aplicabilidade do herbário IFSR em São Paulo, por atender profissionais de outras instituições, que fazem uso de seus materiais. Estes resultados sinalizam o distanciamento no próprio espaço acadêmico da UEPA, uma vez que o herbário instalado no CCSE não converge visibilidade e integração.

Quanto às contribuições do herbário à universidade e a sociedade observou-se que as ideias de conservação/preservação e pesquisas interdisciplinares se fizeram presentes nas falas dos entrevistados, como exemplificado por um aluno de ciências da religião: um herbário proporciona aos alunos e a comunidade conhecimentos mais aprofundado das espécies existentes em nossa região, além de apresentar a cultura de nosso povo (A.R.S., 21 anos). Nas interpretações de Fagundes e Gonzalez [27] os herbários, em uma perspectiva que alia o conhecimento científico como estratégia de envolvimento pedagógico, auxiliam práticas docentes para muitas disciplinas diferentes. Para Bessa [28] as coleções botânicas em forma de acervo didático para as aulas de biologia do ensino médio são eficientes devido à riqueza de materiais e informações, proporcionando aos alunos contato com organismos e uma maior interação pelo manuseio.

As coleções botânicas, dentre as diversas funções que desempenham, promovem aprendizagens diferentes sobre a diversidade da vida, oportunizando aos alunos contato com uma variedade de espécies que podem observar, direta ou indiretamente [29], além de suscitar senso crítico. Desta forma, a exposição do MFS sempre destina um espaço para as espécies ameaçadas de extinção com base na Lista Nacional Oficial de Espécies da Flora Ameaçadas de Extinção, Portaria ${ }^{\circ} 443$ do Ministério do Meio Ambiente [30], apresentando os seguintes espécimes: Cedro (Cedrela odorata L.); Andiroba (Carapa guianensis Aublet); Cumaru (Dipteryx odorata (Aubl.) Willd.); Mogno (Swietenia macrophylla King); Ucuúba (Virola surinamensis (Rol. ex Rottb.) Warb.). A visualização destas amostras suscitou surpresas e reflexões nos entrevistados, que verbalizaram a importância do acervo na proteção da biodiversidade: o herbário pode ajudar as pessoas a se conscientizarem da necessidade de se manter essas plantas que estão em extinção (D. dos S., 19 anos). 


\subsection{O Herbário Virtual do MFS}

Após 10 meses de atividades de planejamento e execução, o herbário virtual tornou-se público com a criação da página disponível em paginas.uepa.br/herbariomfs (Figura 2). O espaço está hospedado no servidor da UEPA e o acesso é permitido através do site da universidade $h t t p: / / w w w . u e p a . b r / p o r t a l / i n d e x . p h p$ (Figura 3) ou com a inserção de palavraschave no site de busca Google.
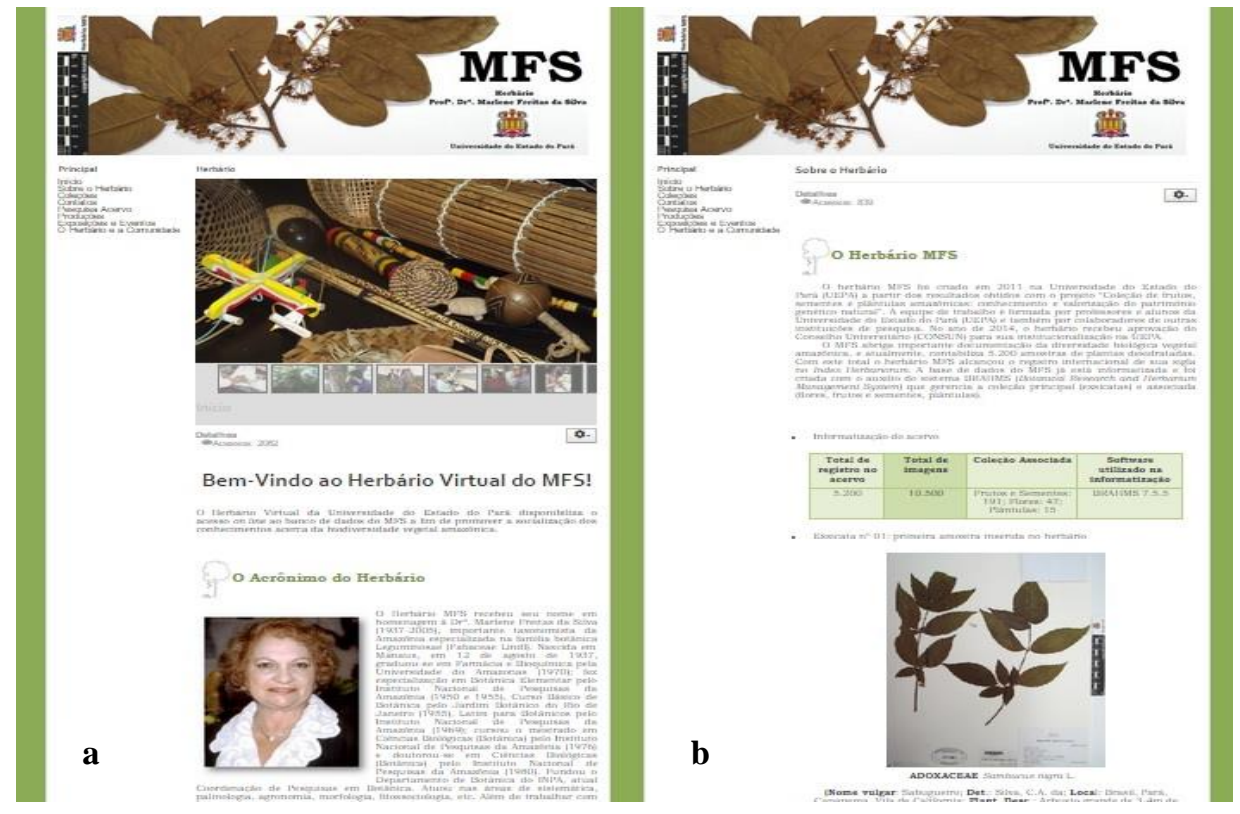

Figura 2: (a) Página inicial, com espaço dedicado à homenageada e o acrônimo MFS, Profa. Dra. Marlene Freitas da Silva; (b) Apresentação de um histórico do herbário.

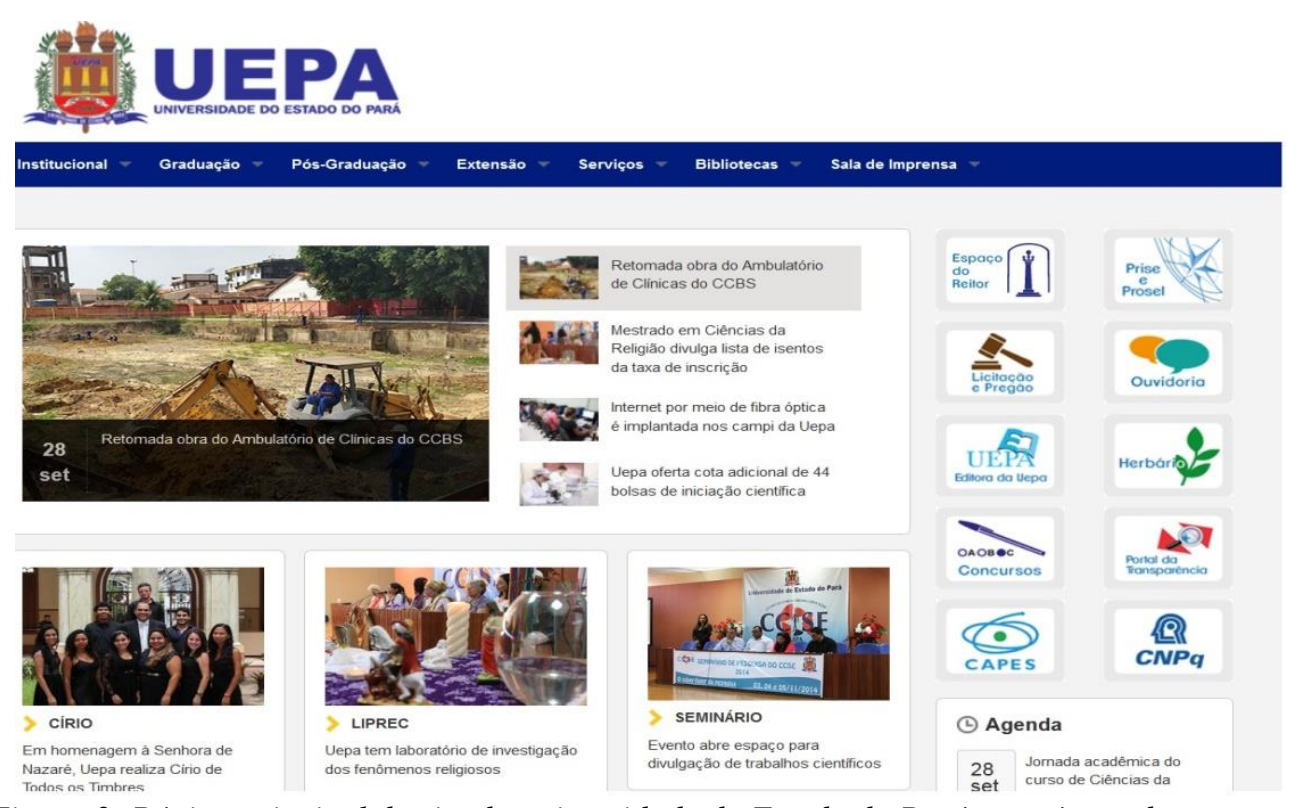

Figura 3: Página principal do site da universidade do Estado do Pará, com ícone de acesso ao herbário virtual MFS.

No espaço virtual é possível conhecer toda a coleção, com 5.800 amostras, distribuídas em 2.368 espécies, pertencentes a 886 gêneros e 173 famílias botânicas. Há também a coleção de flores, frutos, sementes e plântulas, que estão associadas a 210 registros de exsicatas. De cada espécime é possível consultar dados nas áreas de Sistemática e Morfologia, Ecologia (forma de 
vida, distribuição espacial), Fitossociologia (floração e frutificação) Georeferenciamento e Etnobotânica. Hopkins [31] e Vargas et al [32] evidenciaram os herbários on line como importante instrumento de pesquisa e curadoria, reduzindo bastante o tempo envolvido na busca de informações, sem custos e prevenindo possíveis danos aos exemplares em caso de empréstimos.

O acervo digital do MFS ocupa 79 MB no DATABASE e é composto por 9.783 imagens, com o total de 27 GB no seu banco. Das imagens digitalizadas, 500 foram corrigidas e novamente fotografadas em virtude do baixo nível de nitidez, fato inviável para um herbário virtual. De posse das imagens, o visitante poderá pesquisá-las para diversos fins, inclusive taxonômicos, sendo importante observar os detalhes da exsicata, como os dados da etiqueta e a morfologia da amostra botânica.

\subsection{Visibilidade e disponibilização on line}

A elaboração da página do herbário virtual levou em consideração tanto as necessidades técnicas do acervo, quanto as expectativas expressadas nas entrevistas. Portanto, foram incluídos tópicos no menu ferramentas que representaram as palavras-chave verbalizadas na ocasião da exposição: cultura, biodiversidade, comunidades amazônicas, divulgação, acesso a trabalhos científicos na área etc. Outras informações complementam esse menu, auxiliando a pesquisa dos espécimes (por meio do provedor BOL) e demais atividades vinculadas ao herbário, as quais encontram-se dispostas a seguir:

1. Sobre o herbário: histórico do MFS, dados quantitativos das coleções (número de amostras, coleção associada, número de imagens etc.) e qualitativos (contribuições para pesquisas científicas, ferramentas de ensino, premiações de projetos etc.).

2. Coleções: apresentação das Exsicatas, Flores, Frutos, Sementes, Plântulas, Briófitas e a coleção temática de produtos Etnobotânicos.

3. Eventos: exposições e oficinas promovidas pelo herbário, com a participação de alunos e professores em eventos científicos e de divulgação local. Além disso, o site fornece suporte bibliográfico de referência, como um complemento as informações botânicas e de áreas afins, sendo possível buscar lista de publicações de livros, artigos e de reportagens publicadas em jornais e revistas.

4. Herbário e a comunidade: expedições em comunidades no estado do Pará para coleta de amostras botânicas e incremento do acervo.

5. Novidades: divulgação de acontecimentos/eventos científicos na área da botânica.

6. Contatos: nomes e endereços da equipe de trabalho.

7. Produções: publicações científicas vinculadas ao herbário (artigos, trabalhos completos, resumos, oficinas, material didático etc.).

8. Pesquisa Acervo: link direto com o Brahms on line, ferramenta que encaminha o visitante ao banco de dados do herbário MFS e possibilita-o realizar pesquisas em seu acervo, disponível em <http://herbaria.plants.ox.ac.uk/bol/mfs $>$ (Figura 4). 
Home Explore

\section{Herbário MFS - Universidade Do Estado Do Pará}

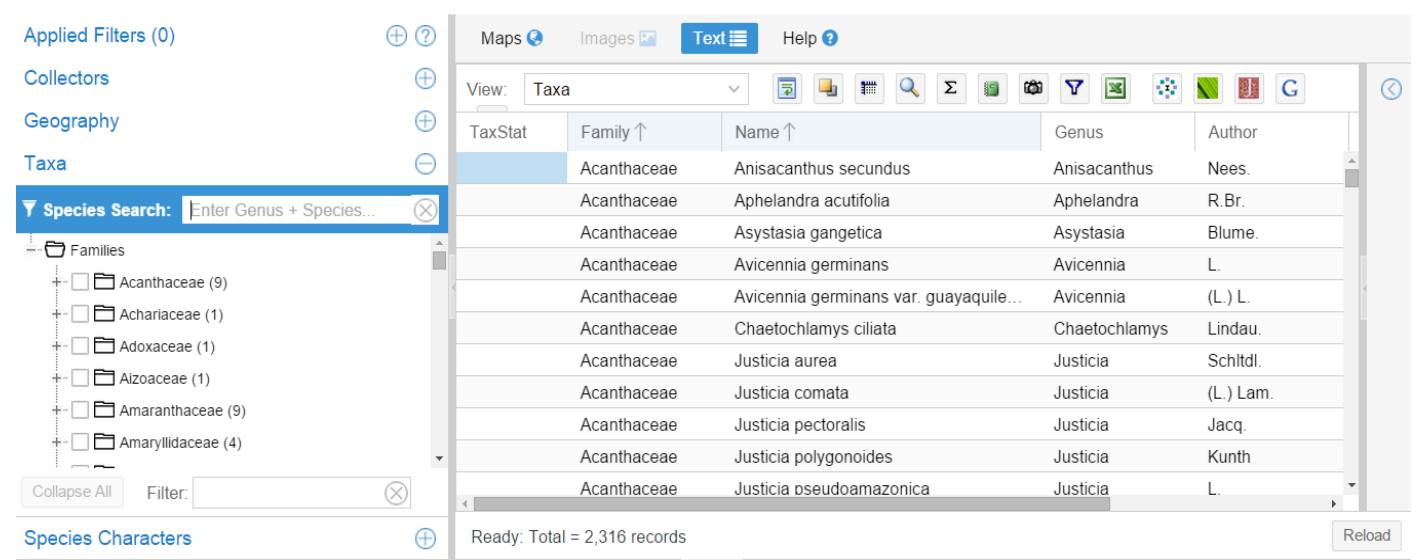

Figura 4: Banco de dados do MFS disponível na página Brahms on line.

O acesso público e aberto aos dados da biodiversidade vegetal do herbário da UEPA representa "via de mão dupla", ou seja, ao mesmo tempo em que favorece o crescimento científico da universidade, por alunos e professores, torna as coleções do MFS visíveis e valorizadas como patrimônio da instituição. Segundo Peixoto et al [33] os herbários virtuais ampliam a visibilidade e o prestigio das coleções biológicas, permitindo melhorar na sua qualidade. Ademais, para estes autores o benefício preponderante do compartilhamento de dados se encerra no avanço científico e tecnológico e nas trocas entre diferentes áreas de conhecimento.

O site foi divulgado também por meio de redes sociais, como o Facebook, através da criação de uma página para o MFS que informa sobre eventos científicos, materiais didáticos, reportagens, vídeos, dentre outros, com links direto para o herbário virtual. Esta publicação foi uma alternativa para dar mais abertura a visitantes externos da página da UEPA, ou seja, aqueles que estão fora do ambiente universitário. $\mathrm{O}$ site também foi exposto em revistas de circulação local (Saber Amazônia) e jornais eletrônicos.

A possibilidade de livre acesso aos conteúdos do herbário virtual ocasiona um desdobramento maior para a capacitação e formação docente e discente, bem como da sociedade em geral. Nos seus cinco anos de existência o MFS mantém o compromisso com o desenvolvimento científico e tecnológico da UEPA. Desde então, vem contribuindo com a formação de alunos, oferecendo estágios (35 alunos) e orientando bolsistas (12 alunos do Programa Institucional de Bolsas de Iniciação Científica/Conselho Nacional de Desenvolvimento Científico e Tecnológico (PIBIC/CNPq), 4 do Programa Institucional de Bolsas de Iniciação em Desenvolvimento Tecnológico e Inovação (PIBITI/CNPq) além de auxiliar nas aulas de graduação (Curso de Ciências Naturais, Engenharia Florestal e o Plano Nacional de Formação de Professores-PARFOR) e no Programa de Pós-graduação - Mestrado em Ciências Ambientais (Contribuição aos projetos de Etnobotânica).

Com os programas de extensão, tem sido atuante nos projetos "Uepa na Comunidade" e "Educação Ambiental em Ação: práticas pedagógicas, cidadania e lazer para crianças da comunidade da Vila da Barca, Belém-Pará", que buscam um maior estreitamento entre universidade e sociedade, oportunizando o estudo virtual de materiais diversificados, com o envolvimento de escolas e comunidades. De acordo com o Plano Nacional de Extensão Universitária [34] a extensão é o processo educativo, cultural e científico que articula o Ensino e a Pesquisa de forma indissociável e viabiliza a relação transformadora entre Universidade e Sociedade.

A difusão eletrônica da coleção do MFS permite também conhecer um pouco do espaço físico, que contempla uma biblioteca particular, com obras na área da botânica e afins, além de manuais técnicos para manejo e coleta de materiais em campo; vídeos educativos; treinamentos de rotina de herbário e tutoriais para sistema de gerenciamento de banco de dados. 


\section{CONCLUSÃO}

O acervo botânico do MFS é uma ferramenta de amplo significado para o ensino, pesquisa e extensão, sendo, a implantação do herbário virtual na UEPA o primeiro passo que converge na aproximação entre produção de conhecimento e socialização. Quantidades de acessos à página e entrevistas dadas à assessoria de imprensa da instituição e de outras emissoras de televisão, abriram os caminhos para a popularização e atuação do herbário MFS. Entende-se que há necessidade de propor estratégias para aproximar públicos diferenciados, e isso é tarefa para curadores, diretores e outros profissionais que trabalhem com colecionamentos. Nesse aspecto, a disponibilização on line amplia a capacidade brasileira em conservar e utilizar a biodiversidade.

\section{REFERÊNCIAS BIBLIOGRÁFICAS}

1. Fry C. Os Caçadores de Plantas: as aventuras dos Maiores Exploradores Botânicos do Mundo. Ed. Europa, São Paulo, 2014. 63p.

2. Joly CA, Haddad CF, Verdade LM, Oliveira MCD, Bolzani VDS, Berlinck RG. Diagnóstico da pesquisa em biodiversidade no Brasil. Revista USP 2011 Mar/Maio;89:114-133.

3. Peixoto AL, Barbosa MR de V, Menezes M, Maia LC. Diretrizes e estratégicas para a modernização das coleções botânicas brasileiras com base na formação de taxonomistas e na consolidação de sistemas integrados de informação sobre biodiversidade. Diretrizes e Estratégias para a Modernização de Coleções Biológicas Brasileiras e a Consolidação de Sistemas Integrados de Informação sobre Biodiversidade. Ministério da Ciência e Tecnologia, Brasília 2006, p.145-182.

4. Cavalheiro L, Pires AFP, Reis C, Borges FR, Pinheiro MHO, Vilela-Santos MC, Arruda R. O Herbário "Centro-Norte-Mato-Grossense" (CNMT): Documentação Botânica Para o Ensino, Extensão e Pesquisa. Scientific Electronic Archives 2013 Set/Dez;4:25- 30.

5. Costa F, Castilho C, Drucker DP, Kinupp V, Nogueira A, Spironello W. Flora. In: de Oliveira ML, Baccaro FB, Braga-Neto R, Magnusson WE. (Orgs.). Reserva Ducke: A biodiversidade amazônica através de uma grade — Manaus: Áttema Design Editorial, 2008. 170p.

6. Góes-Neto LA, Pietrobom MR. Novos registros de samambaias para a Amazônia Brasileira. Rodriguésia-Instituto de Pesquisas Jardim Botânico do Rio de Janeiro 2013 Jun;63(4): 1151-1155.

7. Mittermeier RA. Wilderness and Biodiversity Conservation. Proceedings of the National Academy of Sciences 2003 Jul;100(18): 10309-10313, doi: 10.1073/pnas.1732458100.

8. Imazon-Instituto do Homem e Meio Ambiente da Amazônia. Disponível em: <http://imazon.org.br/>. Acesso: 10 Mar. 2015.

9. Peixoto AL, Morim MP. Coleções Botânicas: documentação da biodiversidade brasileira. Ciência e Cultura $2003 \mathrm{Jul} / \mathrm{Set}$; 55(3): 21-24.

10. Saraiva AM, Canhos DAL. Polinizadores no Brasil - contribuição e perspectivas para a biodiversidade, uso sustentável, conservação e serviços ambientais. EDUSP, São Paulo, 2012. 488p.

11. CRIA - Centro de Referência em Informação Ambiental. Disponível em: <www.cria.org.br>. Acesso: 14 Jan. 2015.

12. Herbário Virtual da Flora e dos Fungos - INCT. Disponível em: <http://inct.florabrasil.net/>. Acesso: 10 Maio 2015.

13. INDEX HERBARIORUM: A global directory of public herbaria and associated staff. New York Botanical Garden's Virtual Herbarium. Disponível em: <http://sweetgum.nybg.org/ih/>. Acesso: 11 Jan. 2015.

14. GBIF-Global Biodiversity Information Facility. Disponível em: <http://www.gbif.pt/.> Acesso: 24 Ago. 2015.

15. Minayo MCS. Pesquisa social: teoria, método e criatividade. 23. ed. Petrópolis, RJ: Vozes, 2004. 80p.

16. Boni V, Quaresma SJ. Aprendendo a entrevistar: como fazer entrevistas em Ciências Sociais. Revista Eletrônica dos Pós-Graduandos em Sociologia Política da UFSC 2005 Jan/Jul;2(1):68-80.

17. BRAHMS-Botanical Research and Herbarium Management System. Atualizado em Junho 2010. Traduzido por Regina Célia Martins da Silva. Disponível em: <http://herbaria.plants.ox.ac.uk/bol/content/documentation/AboutBRAHMS2010-pt.pdf>. Acesso: 20 Maio 2015.

18. Lista de Espécies da Flora do Brasil. Jardim Botânico do Rio de Janeiro. Disponível em: <http://floradobrasil.jbrj.gov.br/>. Acesso: 05 Fev. 2015. 
19. Tropicos.org. Missouri Botanical Garden. Disponível em: 〈http://www.tropicos.org/>. Acesso: 10 Abr. 2015.

20. The New York Botanical Garden - NYBG. Disponível em: 〈www.nybg.org〉. Acesso: 10 Abr. 2015.

21. Conn BJ. (ed.) Herbarium Information Standards and Protocols for Interchange of Data - HISPID3. 3 v. Sydney: Royal Botanic Gardens. 1996. Disponível em: <http://www.tdwg.org/standards/110/〉. Acesso: 17 Mar. 2015.

22. Filer DL. BRAHMS WebConnect: website development and publishing online from BRAHMS. 2012. Disponível em: <http://herbaria.plants.ox.ac.uk/bol/content/documentation/BRAHMSWebConnect.pdf>. Acesso: 10 Maio 2015.

23. Liddell A. BRAHMS online: Installation Guide. 2012. Disponível em: <http://herbaria.plants.ox.ac.uk/bol/Content/Projects/brahms/Resources/BOL_Setup.pdf>. Acesso: 10 Maio 2015.

24. Peixoto AL, Maia LC. Manual de Procedimentos para Herbários. INCT-Herbário virtual para a Flora e os Fungos. Editora Universitária UFPE, Recife, 2013. 53p.

25. Záchia RA. A evolução do conhecimento sobre a flora Rio-Grandense nos últimos 20 anos e a importância das coleções científicas no espaço acadêmico da universidade pública - os exemplos do herbário e do Jardim Botânico da Universidade Federal de Santa Maria. Ciência e Natura 2014 ed. Especial;36:294-301, doi:10.5902/2179460X13190.

26. dos Santos FS. O herbário IFSR e sua importância científica e educacional. Revista Hipótese 2015 Abr;1(1):15-23.

27. Fagundes JÁ, Gonzalez CEF. Herbário Escolar: suas contribuições ao estudo da Botânica no Ensino Médio. 2014. Disponível em: < http://www.diaadiaeducacao.pr.gov.br/portals/pde/arquivos/16758.pdf>. Acesso: 16 Ago. 2015.

28. Bessa MG. Montagem de Coleção Botânica para o auxílio do ensino de biologia no Ensino Médio. Brasília, 2011. Disponível em: <http://repositorio.uniceub.br/bitstream/235/6430/1/20803295.pdf>. Acesso: 10 Jun. 2015.

29. Silva JN, Ghilardi-Lopes NP. Botânica no Ensino Fundamental: diagnósticos de dificuldades no ensino e da percepção e representação da biodiversidade vegetal por estudantes. REEC: Revista electrónica de enseñanza de las ciencias 2014 Set/Dez;13(2): 115-136.

30. MMA-Ministério do Meio Ambiente. Portaria $n^{\circ} 443$, de 17 de dezembro de 2014. Lista Nacional Oficial de Espécies da Flora Ameaçadas de Extinção. Disponível em: $<$ http://www.mma.gov.br/responsabilidade-socioambiental/agenda-21/itemlist/category/51especies-ameacadas-de-extincao>. Acesso: 16 Jun. 2015.

31. Hopkins M. Herbários virtuais: Conceitos, estado da arte, usos e recomendações. Belém, 2005. Disponível em: <www.cria.org.br/cgee/documentos/herbariovirtual.doc〉. Acesso: 12 Mar. 2015.

32. Vargas BC, Nakajima JN, Romero R. Acervo Digital do Herbarium Uberlandense: Parque Nacional da Serra da Canastra, MG. Minas Gerais, 2007. Disponível em: <http://www.seer.ufu.br/index.php/horizontecientifico/article/viewFile/3889/2894>. Acesso: 12 Jun. 2015.

33. Peixoto AL. Coleções Botânicas: objetos e dados para a ciência. Cultura material e patrimônio da Ciência e Tecnologia. $1^{\circ}$. ed. Rio de Janeiro: Museu da Astronomia e Ciências Afins 2009 1:10-22.

34. Brasil. Plano nacional de extensão universitária, edição atualizada 2000/2001. Departamento de Política do Ensino Superior, SESu/MEC. Fórum de Pró-Reitores de Extensão das Universidades Públicas Brasileiras. Brasília, 1999. p.1-17. 